\title{
Case series on congenital malaria from a tertiary care hospital in North Eastern India
}

\author{
Saugata Choudhury ${ }^{1}$, Joydeep Das ${ }^{2}$
}

${ }^{1}$ Assistant Professor, Department of Pediatrics, B. C Roy Post Graduate Institute of Pediatric Sciences, ${ }^{2}$ Professor and Head, Department of Pediatrics, Jagannath Gupta Institute of Medical Science, K. P. Mondal Road, Buita, Budge Budge, Kolkata: 700137

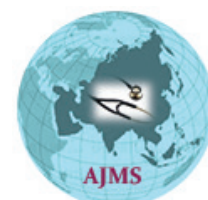

A B S T R A C T

Malaria in early life is due to transfer of parasitized maternal red blood cell across placenta or direct transfer of parasite from placental syncytotrophoblast. Congenital malaria is defined as malaria acquired from mother in prenatal or perinatal period. Most of the cases in endemic area, passive transfer of high amount of maternal lgG antibody binds to malarial antigen and various components of parasites giving rise to various atypical clinical presentation. This case series will help neonatologist to think malaria in all non-specific symptoms of inconsolable cry, poor feeding, lethargy, even persistence of physiological jaundice. Very few reports of congenital malaria from India is reported in literature. Our series of five cases will address these few atypical symptoms.

Key words: Congenital; Malaria; Placenta; Syncytotrophoblast

\section{Access this article online}

Website:

http://nepjol.info/index.php/AJMS DOI: 10.3126/ajms.v12i9.37273

E-ISSN: 2091-0576

P-ISSN: 2467-9100

Copyright (c) 2021 Asian Journal of Medical Sciences

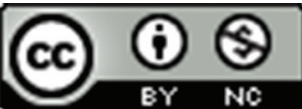

This work is licensed under a Creative Commons Attribution-NonCommercial 4.0 International License.

\section{INTRODUCTION}

The transmission of malaria cannot be controlled in India due to rapid urbanization with high population density, improper drainage of water and clogging of drainage by garbage composed of plastic. It has become a perennial event. Newborn does not have sufficient muscle mass to produce shakes of chill. In addition, huge amount of antimalarial antibody binds to merozoites, restrict free movement of parasite and invasion of babies red blood cells. Moreover, high fetal hemoglobin ${ }^{1}$ and low PABA (para aminobenzoic acid ${ }^{2}$ in breast fed babies prevents parasite multiplication inside RBC. All these factors are responsible for subclinical presentation of congenital malaria. Younger generation of physicians fails to consider malaria when a newborn presented with common neonatal complaints like persistence of physiological jaundice, exaggerated physiological anemia of infancy and other non-classic features. Most of the case is diagnosis by retrospective input from pathologist while examining smear for blood count. Predominant clinical features of our five cases is as follows.

Case 1: Inconsolable cry with exaggerated physiological anemia of infancy.

Case 2: Inconsolable cry and feeding problem.

Case 3: Progressive pallor with organomegaly.

Case 4: Refusal to feed, lethargy suggestive of sepsis.

Case 5: Persistence of physiological jaundice.

Case 1: Four weeks old male neonate presented with inconsolable cry, excessive irritability and progressive pallor 
for last 10 days. He is born at term by normal delivery, cried well at birth with a birth weight of $3 \mathrm{~kg}$. He was sucking well but not showing any sign of satiety or well-being. His sleep was reduced from before and almost awake in both day and night. Pallor appears unusual at 4 weeks in a term baby for which all investigation was done except malaria but diagnosis was done by pathologist who has seen the peripheral smear not by clinician.

Case 2: Three weeks old male neonate born at term with a birth weight of $3.5 \mathrm{~kg}$ with uneventful antenatal, natal and post-natal history presented with inconsolable cry, refusal to feed for last 3 days. On examination mild pallor with borderline organomegaly. Mother has no complaints with respect to malaria. To find out the cause of inconsolable cry, sepsis screen, blood culture, lumber puncture was done but all parameters were normal except borderline low hemoglobin. As a part of evaluation of late onset sepsis band cell and toxic granule were requested in peripheral smear and diagnosis was made by pathologist.

Case 3: Eight weeks old female neonate presented with moderate to severe pallor with organomegaly for the past two weeks. Considering large organomegaly and pallor hemoglobin electrophoresis and other differentials of hemolytic anemia was sent and appeared normal. The laboratory technician and pathologist who compared the peripheral smear with hemoglobin electrophoresis diagnosed of malaria.

Case 4: Three weeks old preterm small for date born to a primi mother by caesarian section with a birth weight of $1.8 \mathrm{~kg}$, cried well and discharged on day 5 . Mother complaints of one episode of staring look like fits and refusal to feed since morning. The baby was admitted with the diagnosis of late onset sepsis with meningitis and started IV antibiotics. After admission baby got multiple fits with positive sepsis screen. History from the mother was conclusive as she discloses about her falciparum malaria one week before delivery treated by gynecologist.
Case 5: Three weeks old male baby at term weighing $3.5 \mathrm{~kg}$ born to a multigravida mother by normal delivery presented to outpatient department with persistence of jaundice since birth. As icterus is up to the sole, the senior resident did send blood test which was confirmed of vivax malaria.

This table shows three mothers had malarial fever at 5 , 6 and 8 months of gestation. Retrospective analysis of reports showed mother 1 and mother 2 had vivax malaria whereas mother 3 had suffered from falciparum. They were unable to show details of treatment. On repeated asking they stated that local physician did not prescribed any radical cure in the fear of fetal toxicity. Remaining two mother had no symptoms of malaria in pregnancy but both babies are vivax positive in peripheral smear. Rest of the table depicts blood counts, bilirubin and $\mathrm{C}$ reactive protein of different cases.

\section{DISCUSSION}

In this series inconsolable cry and refusal to feed is predominant nonspecific symptoms, the exact cause of these behavior is not known. The metabolic products of malarial parasites and biomolecules released in blood during rupture of a schizont induce some excitatory cytokines. One of the known biomolecule is quinolinic acid which has excitatory effect on NMDA receptors of the brain. ${ }^{3}$ Moreover hypoxia arising out of subclinical hemolysis is also responsible. Combination of hypoxia, clogging of microcirculation of brain and excitotoxic neurochemical is responsible for one episode of seizure in case 4. Refusal to feed may be attributable to stimulation of lateral hypothalamus by cytokines. Progressive pallor, jaundice and organomegaly does not need any explanation as malaria causes intravascular hemolysis. Prolonged interval between birth and symptoms may be attributable to transmission in late trimester, during delivery or may be presence of passive antibody from mother. Transfer of high amount of $\operatorname{IgG}$ antibody, ${ }^{4,5}$ attaches different parts of parasite leading to less mobility, less RBC penetrance

\begin{tabular}{|c|c|c|c|c|c|c|c|c|}
\hline & \multirow{2}{*}{$\begin{array}{c}\mathrm{Hb} \\
\mathrm{Gm} \%\end{array}$} & \multirow[t]{2}{*}{ TLC } & \multirow[t]{2}{*}{ DC } & \multirow{2}{*}{$\begin{array}{c}\mathrm{Bil}(\mathrm{D} / \mathrm{ID}) \\
\mathrm{mg} / \mathrm{dl}\end{array}$} & \multirow{2}{*}{$\begin{array}{l}\text { CRP } \\
\mathrm{mg} / \mathrm{dl}\end{array}$} & \multirow[t]{2}{*}{ Trophozoite } & \multicolumn{2}{|c|}{ Maternal malaria status } \\
\hline & & & & & & & Fever/timeline & Microscopy \\
\hline Case 1 & 7.5 & 8500 & $\begin{array}{l}\text { N60 } \\
\text { L37 }\end{array}$ & $7(1.5 / 5.5)$ & -ve & P.vivax & +ve,5 months & $\begin{array}{l}\text { Trophozoites } \\
\text { of vivex }\end{array}$ \\
\hline Case2 & 15 & 6700 & $\begin{array}{l}\text { N68 } \\
\text { L30 }\end{array}$ & $8(1.5 / 6.5)$ & -ve & $P$ vivax & +ve, 6 months & $\begin{array}{l}\text { Trophozoites } \\
\text { of vivex }\end{array}$ \\
\hline Case 3 & 7.8 & 6500 & $\begin{array}{l}\text { N65 } \\
\text { L35 }\end{array}$ & $13(3 / 10)$ & -ve & $P$ vivax & -ve & -ve \\
\hline Case 4 & 16 & 22000 & $\begin{array}{l}\text { N82 } \\
\text { L18 }\end{array}$ & $12(5 / 7)$ & $+\mathrm{ve}$ & P falciparum & +ve, 8 months & $\begin{array}{l}\text { Trophozoites } \\
\text { of falciparum }\end{array}$ \\
\hline Case 5 & 14.5 & 7800 & $\begin{array}{l}\text { N72 } \\
\text { L28 }\end{array}$ & $18(2 / 16)$ & -ve & $P$ vivax & -ve & -ve \\
\hline
\end{tabular}


and few erythrocytic cycle which is partially responsible for nonclassic and delayed presentation. Case number 4 , which is the only case of falciparum malaria in our series mimics sepsis with systemic inflammatory response syndrome can be attributable to high parasite load in falciparum, and liberation of profuse pro and anti-inflammatory cytokines. ${ }^{6}$ No symptoms and negative microscopy of two mothers (Table 1) is really difficult to explain but in holoendemic area there can be recrudescence of old infection from liver during late pregnancy specially when radical cure was incomplete and colonization of placenta by hypnozoites. ${ }^{2}$

Potentially life threatening condition without any potential clinical signs and symptom is really a challenge to pediatrician, hope this series will generate positive thought in treating physician so that no congenital malaria is missed.

\section{REFERENCES}

1. Erica MW Billig, Philip G McQueen and F Ellis McKenzie. Foetal haemoglobin and the dynamics of paediatric malaria. Malar J.
2012; Article No: 396.

https://doi.org/10.1186/1475-2875-11-396

2. Kicska GA, Ting LM, Schramm VL and Kim K. Effect of Dietary p-Aminobenzoic Acid on Murine Plasmodium yoelii Infection. The Journal of Infectious Diseases. 2003; 188 (11): 1776-1781.

https://doi.org/10.1086/379373

3. Idro R, Marsh K, John CC and Charles RJ Newton. Cerebral Malaria; Mechanisms of Brain Injury and Strategies For Improved Neuro-Cognitive Outcome. Pediate Res. 2010; 68(4): 267-274. https://doi.org/10.1203/PDR.0b013e3181eee738

4. Hviid L and Salanti A. VAR2CSA and protective immunity against pregnancy-associated Plasmodium falciparum malaria. Parasitology. 2007;134(Pt 13):1871-1876.

https://doi.org/10.1017/S0031182007000121

5. Gathwala G, Dalal P and Gupta M. Congenital malaria with atypical presentation: A series of three case reports. Journal of Clinical Neonatalogy. 2015; 4(3):206-208. https://doi.org/10.4103/2249-4847.154128

6. Punta VD, Gulletta M, Matteelli A, Spinoni V, Regazzoli A and Castelli F. Congenital Plasmodium vivax malaria mimicking neonatal sepsis: a case report. Malar J. 2010;9:63. https://doi.org/10.1186/1475-2875-9-63

\section{Author's Contribution: \\ SC - Written the manuscript; JD - Collected the cases.}

Work Attributed to:

Department of Pediatrics, Institute of Child health, Jagannath Gupta Institute of Medical Sciences and B. C Roy Post Graduate Institute of Pediatric Sciences.

Orcid ID:

Dr Joydeep Das - (1) http://orcid.org/0000-0002-6198-001X

Dr Saugata Choudhury - (1) http://orcid.org/0000-0003-2565-9250

Source of Funding: None, Conflict of Interest: None. 